\title{
Equações algébricas e decisão do melhor investimento
}

\author{
Ronie Dario Jeferson da Silva
}

\begin{abstract}
Resumo
Este trabalho explora a matemática envolvida nos métodos determinísticos de análise de investimentos baseados no Valor Presente Líquido (VPL) e na Taxa Interna de Retorno (TIR) de um projeto econômico-financeiro. Em especial, estrutura-se os conceitos e resultados envolvendo a existência e unicidade da TIR para um dado fluxo de caixa, mostrando como a utilização das equações algébricas pode ter grande importância na abordagem de problemas financeiros práticos.
\end{abstract}

Palavras-chave: equações algébricas, valor presente líquido, taxa interna de retorno.

\section{Abstract}

This work explores the mathematics involved in the deterministic methods of investment analysis based on the Net Present Value (NPV) and the Internal Rate of Return (IRR) of an economicfinancial project. In particular, the concepts and results involving the existence and uniqueness of the IRR for a given cash flow are structured, showing how the use of algebraic equations could have great importance in approaching practical financial problems.

Keywords: algebraic equations, net present value, internal rate of return.

\section{Introdução}

Frequentemente nos deparamos com a necessidade de optar entre um ou outro investimento, empréstimo pessoal, financiamento habitacional, entre outras operações financeiras.

Por exemplo, se decidirmos investir em renda fixa, teremos à disposição a Caderneta de Poupança, os Certificados de Depósito Bancário (CDB's), os títulos públicos federais (Tesouro Direto), e uma variedade de outras opções. Cada investimento tem sua taxa de juros definida em função do prazo de aplicação e dos riscos envolvidos. Por outro lado, se precisamos tomar um empréstimo ou fazer um financiamento, há diversas opções cujas taxas variam em função dos prazos de pagamento e das garantias oferecidas. A maior variedade de opções requer as melhores análises possíveis antes da tomada de decisão.

Decisões envolvendo projetos financeiros podem ser tomadas com melhor assertividade utilizando técnicas relativamente simples de análise do valor do dinheiro no tempo. Uma classe importante destas técnicas corresponde aos métodos determinísticos de análise de investimentos. 
Para uma considerável variedade de problemas a utilização destes métodos pode ser feita por pessoas fora de áreas como administração financeira ou economia. A análise da melhor opção na aquisição de bens de consumo, por exemplo, pode ser explorada no ensino básico e médio, auxiliando as famílias a terem consciência da melhor escolha, ajudando assim no orçamento familiar. Além disso, pode ficar ainda mais clara aos professores de matemática a influência direta de conceitos da matemática básica na escolha de um ou outro projeto financeiro.

A apropriação da matemática envolvida nestes métodos é uma forma de aprimorar a própria utilização dos mesmos, pois pode permitir adaptações de acordo com a situação real.

Objetivamos neste trabalho estruturar adequadamente a matemática dos métodos determinísticos de análise de investimentos baseados nos conceitos de TIR e VPL, conforme explicamos a frente. Em boa parte das vezes, basta entender e aplicar a capitalização composta e inversamente, o cálculo do valor presente de determinados valores. Em diversas outras situações, faz-se necessário estudar as raízes de determinados polinômios, resolvendo equações algébricas. Em particular, é importante saber a quantidade de raízes distintas e a variação de sinal entre elas. Aqui precisaremos utilizar indução finita e algumas ferramentas do cálculo diferencial, como o Teorema de Rolle.

Esperamos que a exploração da matemática envolvida nos métodos possa dar suporte a outras publicações específicas de educação financeira voltadas ao ensino do tema e que possam ser desenvolvidas mais aplicações para utilização por professores de matemática em sala de aula. Neste sentido, procuramos desenvolver exemplos que possam ser utilizados ou adaptados no ensino do tema no nível básico e médio.

Um dos conceitos preferidos pelos analistas financeiros é o de Taxa Interna de Retorno (TIR) de um investimento. Costuma-se defini-la como a taxa de desconto que iguala o valor presente de caixa futuros ao valor do investimento inicial. O conceito preciso está na Definição 2.

Ocorre que uma TIR é uma raiz de um polinômio com grau tão elevado quanto o número de entradas ou saídas de caixa após o investimento inicial. A partir do estudo de equações polinomiais concluise que somente em situações muito específicas haverá uma única TIR. Uma delas é no caso de um fluxo de caixa conhecido como convencional. Este fluxo ocorre, por exemplo, em um investimento em um título público federal (levado ao vencimento) com pagamento semestral de cupom de juros.

No caso de um fluxo de caixa convencional utiliza-se um clássico teorema sobre variações de sinais dos coeficientes de um polinômio para obter como corolário imediato (Teorema 2) a existência e unicidade da TIR. A ênfase do nosso trabalho é sobre esse teorema e suas aplicações, devido ao fato que, essencialmente, este é o único caso tratado nas referências brasileiras e em geral sem muita preocupação com a matemática envolvida, inclusive em materiais oficiais de ensino do tema. Veja por exemplo [4] e [8].

Existem exemplos de ordem prática em que uma TIR sequer existe como número real. Em [3] é exposto um método para análise de um projeto de investimento desse tipo. Apesar disso, em algumas situações afirma-se que neste caso o investimento não possui taxa interna de retorno [6, p199].

A ocorrência de múltiplas TIR's começou a ser estudada a partir do clássico exemplo de [5] sobre prospecção de petróleo. Tornou-se tema de pesquisa em matemática/administração financeira. Veja, por exemplo, [3] e [11], onde são propostos métodos mais avançados.

Quase na sua totalidade, as operações financeiras são realizadas através do regime composto de capitalização de juros (juros compostos), no qual os juros que se formam ao final de cada período 
$k$ pela aplicação da taxa correspondente $i_{k}$, participam da geração de juros do período seguinte. Assim, ao final do tempo $t$, um capital $C_{0}$ transforma-se em um montante $M(t)$ dado por

$$
M(t)=C_{0} \prod_{k=1}^{t}\left(1+i_{k}\right) .
$$

Assumiremos sempre $i_{k} \neq-1$, para todo $k$. A Equação 1 pode ser estendida para o caso de variável contínua, que tem grande utilidade teórica. Porém, isto não se fará necessário no nosso trabalho.

Uma situação particular bastante frequente ocorre quando a taxa de juros acordada na operação financeira é constante, digamos igual a $i$. Neste caso, decorre da Equação 1 que

$$
M(t)=C_{0}(1+i)^{t}
$$

O valor presente do capital $M(t)$ à taxa $i$ é dado por

$$
P(t)=\frac{M(t)}{(1+i)^{t}} .
$$

Na sequência expomos uma ferramenta elementar e útil para estudar um determinando projeto financeiro, o fluxo de caixa. Trata-se de uma representação gráfica do fluxo do dinheiro. ao longo do tempo.

Na terceira seção abordamos nossa primeira técnica determinística para análise de projetos financeiros, o método do Valor Presente Líquido (VPL). Veremos que do ponto de vista da matemática envolvida, o método não oferece grande dificuldade, bastando a aplicação do conceito de valor presente (Equação 3).

O conceito de Taxa Interna de Retorno é discutido na quarta seção. Expomos em detalhes a Regra de Sinais de Descartes, que na sequência é utilizada para a verificação da existência e unicidade da TIR de um fluxo de caixa convencional.

Concluímos o trabalho com uma breve indicação da continuidade natural do assunto, que é o estudo de projetos financeiros com múltiplas taxas de retorno, importante tema de pesquisa na matemática, administração financeira e economia. Em todas as seções apresentamos exemplos práticos que evidenciam a utilidade dos assuntos abordados. Este trabalho está baseado na dissertação de mestrado do primeiro autor [9].

\section{Fluxo de Caixa}

$\mathrm{Na}$ análise, planejamento, ou execução de determinado projeto financeiro é útil visualizar as entradas e saídas de recursos monetários por meio do diagrama denominado fluxo de caixa.

Costuma-se utilizar uma escala horizontal de tempo (ano, mês, dia, etc.) em períodos representados em intervalos contíguos de modo que cada número representa os períodos acumulados. Setas para cima representam as entradas e setas para baixo representam as saídas de caixa.

O diagrama seguinte representa uma saída de caixa hoje no valor de $\mathrm{R} \$ 1.000,00$ com uma entrada de $\mathrm{R} \$ 500,00$ no final do terceiro período e duas entradas de caixa iguais a $\mathrm{R} \$ 400,00$ no final do quinto e do sexto períodos. 


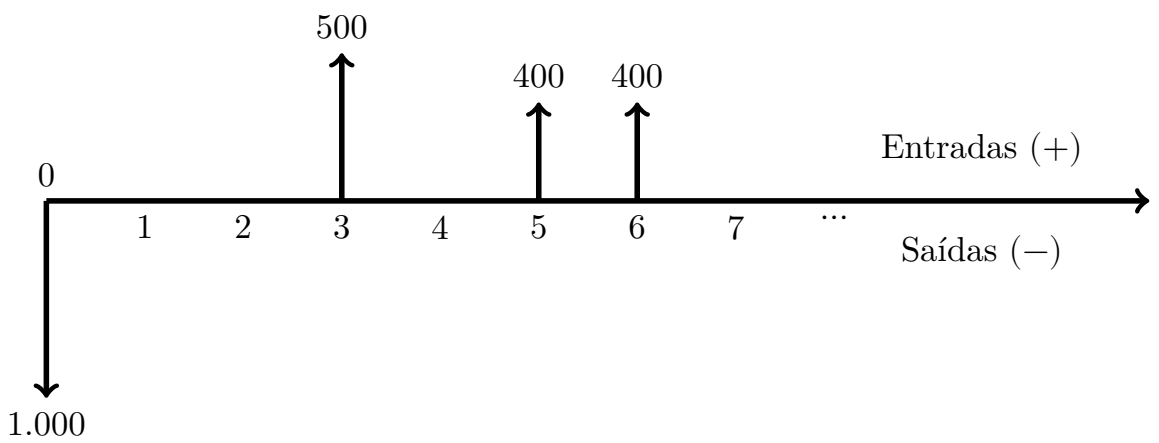

Figura 1: Exemplo de Fluxo de Caixa

Vejamos o caso prático do título negociado no Tesouro Direto chamado de Tesouro IPCA+ com Juros Semestrais (antiga NTN-B), que possui rentabilidade vinculada à variação do IPCA (Índice de Preços ao Consumidor Amplo), acrescida de juros definidos no momento do investimento. Semestralmente há o pagamento de cupom de juros. Finalmente, no vencimento há o pagamento do valor de face (ou valor nominal) do título, juntamente com o pagamento do último cupom de juros.

A Figura 2 ilustra o fluxo de caixa do investimento.

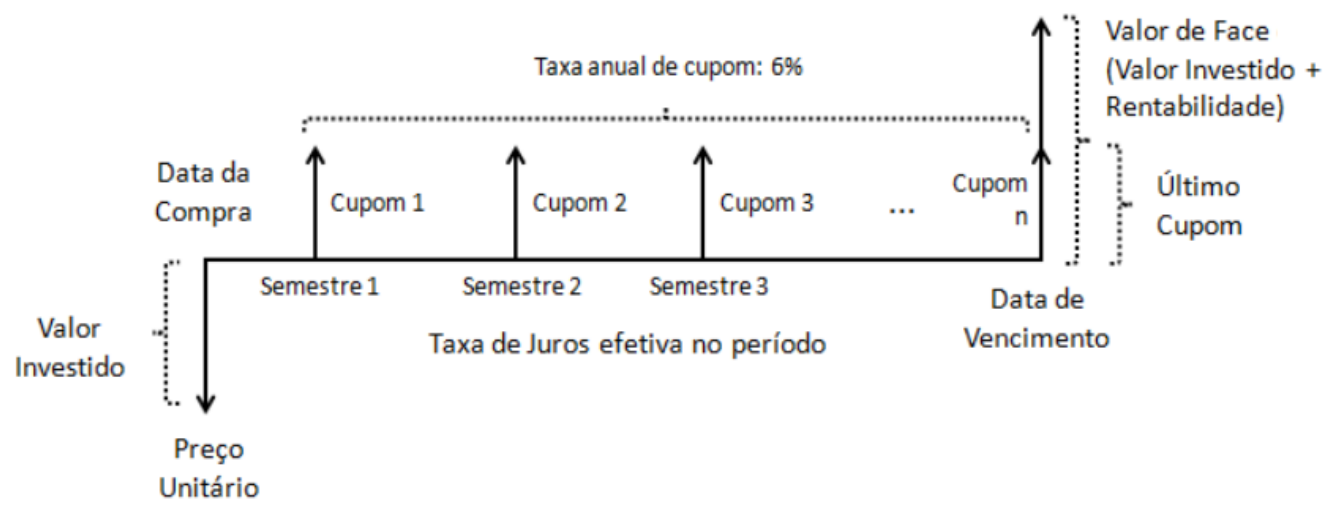

Figura 2: Fluxo de Caixa da NTN-B, Fonte [7]

\section{Valor Presente Líquido (VPL)}

A primeira etapa na análise de um projeto financeiro é o estudo do custo de oportunidade do capital do projeto, também referido como taxa mínima de atratividade (TMA), ou ainda, valor do dinheiro. Trata-se de decidir se é viável a realização do projeto comparando-o com alguma referência de rentabilidade opcional.

No caso de um investimento, uma medida para o custo de oportunidade é a rentabilidade de um 
título de renda fixa com maturação no mesmo período do projeto. No Brasil isto é especialmente relevante, dado que o governo ainda oferece altas taxas de juros nos títulos públicos. No exemplo do título da seção anterior havia um ganho real de $6 \%$ ao ano. A definição desta taxa depende das particularidades e objetivos de cada projeto, assim como das opções disponíveis a quem considera realizá-lo. Vamos denotar a TMA por $\kappa$. Depois de também estabelecido o fluxo de caixa previsto para o projeto, uma maneira de determinar a viabilidade da realização do mesmo é analisar seu valor presente líquido, conforme a definição abaixo. Lembre que $\kappa \neq-1$.

Definição 1. Considere uma série de capitais $c_{0}, \ldots, c_{n}$ e a taxa mínima de atratividade $\kappa$. O valor presente líquido relativo a esta série e taxa é definido como

$$
V=V\left(\kappa, c_{0}, \ldots, c_{n}\right)=c_{0}+\sum_{i=1}^{n} \frac{c_{i}}{(1+\kappa)^{i}} .
$$

A Definição 1 utiliza a Equação 3 para calcular o valor presente de cada capital da série trazendo-o para a data zero, levando em conta a TMA $\kappa$.

Se o projeto tratar de um investimento, $c_{0}$ pode ser entendido como o aporte inicial, seguido de entradas de caixa $c_{1}, \ldots, c_{n}$. Se o VPL for zero, os fluxos de caixa somente conseguiriam recuperar o capital investido e proporcionar o retorno equivalente à taxa mínima. Sendo o VPL positivo, os recursos investidos além de terem sido totalmente recuperados pela taxa $\kappa$, produziram ganho adicional. Em outras palavras, a decisão de investimento gerou riqueza.

Vejamos um exemplo.

Suponha que um pequeno pecuarista deseje adquirir uma propriedade rural no valor de $\mathrm{R} \$ 125.000,00$, visando ampliar seu rebanho. Com a aquisição, suas receitas com a venda de animais aumentariam em $\mathrm{R} \$ 30.000,00$ anuais. Por outro lado, as despesas com a produção iriam atingir mais $\mathrm{R} \$ 7.750,00$ por ano. Supondo que em dez anos a propriedade valerá nominalmente o quanto ela custou e que a TMA é de $18 \%$ ao ano, vejamos se é vantajosa a aquisição. Pela Definição 1, temos

$$
V=-125.000+\sum_{i=1}^{10} \frac{22.250}{(1,18)^{i}}+\frac{125.000}{(1,18)^{10}}=-1.123,52 .
$$

Portanto, a aquisição não é considerada viável nas condições dadas.

A técnica pode ser utilizada para decidir entre duas ou mais opções distintas de projetos econômicofinanceiros. Nesse caso, comparam-se os respectivos valores presentes líquidos das opções envolvidas. Em uma aquisição, por exemplo, a indicação do método é pela escolha do projeto com menor valor presente líquido. Vejamos um caso prático desta situação.

Um imóvel pode ser adquirido de duas formas diferentes. A primeira é à vista, pelo valor de $\mathrm{R} \$$ $170.000,00$ e a segunda é pagando uma entrada de $R \$ 15.000$ e mais 60 parcelas de $R \$ 3.350,00$, sendo que a primeira prestação vence um mês após o fechamento do negócio. Suponha também que há uma opção de aplicação financeira que rende $1 \%$ ao mês (TMA). A aquisição do imóvel à vista tem VPL $V_{1}=170.000,00$, enquanto que para a compra parcelada temos

$$
V_{2}=15.000+\sum_{i=1}^{60} \frac{3.350}{(1,01)^{i}}=165.599,38 .
$$


Como $V_{2}<V_{1}$, temos que a melhor opção para o comprador é a segunda, isto é, comprar a prazo e ir mantendo o saldo aplicado após cada pagamento no período.

Em várias situações práticas a série de capitais é constante, isto é, $c_{i}=R$, para todo $i$. Ou mais geralmente, $c_{i}=R$, para todo $i \geq i_{0}$. Isto pode ocorrer em uma compra parcelada no cartão de crédito ou em um empréstimo pessoal contraído junto a uma instituição financeira. Para séries constantes a partir do tempo $i=i_{0}$, o VPL pode ser diretamente calculado por meio do seguinte teorema.

Teorema 1. $O$ valor presente líquido de uma série de capitais $c_{0}, \ldots, c_{n}$, com $c_{i}=R$, para todo $i \geq i_{0} \geq 0$ e a uma dada taxa mínima de atratividade $\kappa$, é dado por:

$$
V=\sum_{i=0}^{i_{0}} \frac{c_{i}}{(1+\kappa)^{i}}+\frac{R}{\kappa}\left[\frac{(1+\kappa)^{n-i_{0}}-1}{(1+\kappa)^{n}}\right] .
$$

Em particular, para $i_{0}=0$,

$$
V=c_{0}+\frac{R}{\kappa}\left(1-\frac{1}{(1+\kappa)^{n}}\right)
$$

Demonstração. Utilizando a Definição 1 e fazendo $x=\frac{1}{1+\kappa}$, temos

$$
V=\sum_{i=0}^{n} \frac{c_{i}}{(1+\kappa)^{i}}=\sum_{i=0}^{i_{0}} c_{i} x^{i}+R \sum_{i=i_{0}+1}^{n} x^{i}
$$

A soma dos termos $x^{i_{0}+1}$ à $x^{n}$ da progressão geométrica $\left(x^{i}\right)$ é $x^{i_{0}+1}\left(\frac{1-x^{n-i_{0}}}{1-x}\right)$. Substituindo-se $x=\frac{1}{1+\kappa}$, obtêm-se

$$
\sum_{i=i_{0}+1}^{n} x^{i}=\frac{(1+\kappa)^{n-i_{0}}-1}{\kappa(1+\kappa)^{n}}
$$

Como aplicação do Teorema 1, vamos agora considerar o Projeto Faculdade do Pedro, estudante de ensino médio que pretende entrar para uma faculdade particular. Pedro terá até R \$ 500,00 por mês para custear a mensalidade do curso e precisa decidir entre duas possibilidades:

(1) o curso 1 , que custa $R \$ 500,00$ por mês e no qual Pedro espera ter um salário de $R \$ 1.750,00$ após se formar;

(2) e o curso 2 , que custa $R \$ 350,00$ por mês e no qual espera receber $R \$ 1.400,00$ após se formar.

Escolhendo o curso 2, Pedro poderá investir os $\mathrm{R} \$ 150,00$ que sobrarão mensalmente em uma aplicação com rendimento de $0,8 \%$ ao mês. Mais algumas informações:

- os dois cursos duram quatro anos.

- os dois cursos tem uma taxa de matrícula de $\mathrm{R} \$ 500,00$. 
Analisando somente o VPL de cada opção, vejamos qual seria a melhor escolha de curso, supondo que Pedro trabalhe por cinco anos na profissão escolhida recebendo o salário desejado, e que o custo do dinheiro seja de $0,6 \%$ ao mês. Para a primeira opção temos o fluxo de caixa abaixo.

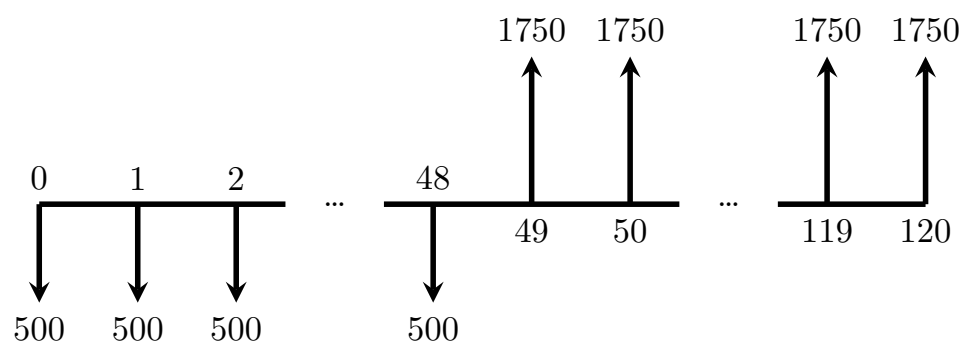

Figura 3: Fluxo de Caixa do Curso 1

Utilizando o Teorema 1, temos

$$
\begin{gathered}
\mathrm{VPL}_{1}=-500-\sum_{i=1}^{48} \frac{500}{(1,006)^{i}}+\sum_{i=49}^{120} \frac{1.750}{(1,006)^{i}}=-500-\frac{500}{0,006}\left(1-\frac{1}{(1,006)^{48}}\right)+ \\
\frac{1.750}{0,006}\left(\frac{(1,006)^{72}-1}{(1,006)^{120}}\right)=76.593,56-20.799,41-500=55.294,15 .
\end{gathered}
$$

Para facilitar a análise da segunda opção vamos dividi-la em duas partes. A primeira (A) refere-se somente às despesas e retornos do curso 2 e tem fluxo de caixa representado abaixo.

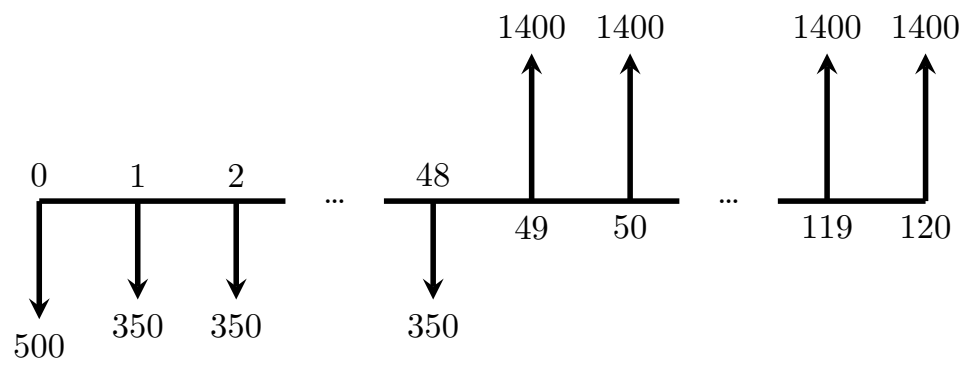

Figura 4: Fluxo de Caixa do Curso A

Novamente pelo Teorema 1 ,

$$
\begin{aligned}
\mathrm{VPL}_{A} & =-500-\sum_{i=1}^{48} \frac{350}{(1,006)^{i}}+\sum_{i=49}^{120} \frac{1.400}{(1,006)^{i}}=-500-\frac{350}{0,006}\left(1-\frac{1}{(1,006)^{48}}\right) \\
& +\frac{1.400}{0,006}\left(\frac{(1,006)^{72}-1}{(1,006)^{120}}\right)=61.274,85-14.559,59-500=46.215,26 .
\end{aligned}
$$

A segunda parte (B) refere-re ao investimento de $\mathrm{R} \$ 150,00$ mensais e possui o fluxo de caixa abaixo. 


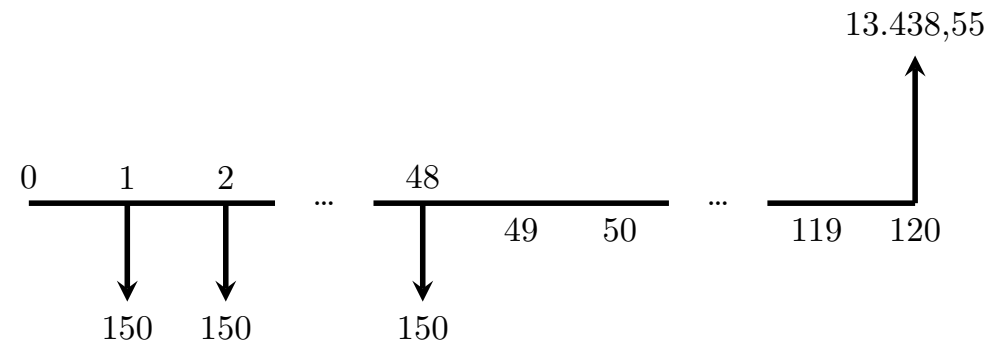

Figura 5: Fluxo do Investimento

A última entrada no valor de $\mathrm{R} \$ 13.438,55$ corresponde ao montante acumulado até o mês 48 , que denotaremos por $S$, corrigido até o último mês. Note que

$$
S=150 \sum_{i=0}^{47}(1,008)^{i}=150\left(\frac{1-(1,008)^{48}}{1-1,008}\right)=8.735,70 .
$$

Pela Fórmula 1, ao final do mês 120 , teremos $M(72)=8.735,70(1,008)^{72}=13.438,55$. Segue que

$$
\mathrm{VPL}_{B}=-\sum_{i=1}^{48} \frac{150}{(1,006)^{i}}+\frac{13.438,55}{(1,006)^{120}}=6.555,33-6.239,82=315,51 .
$$

Finalmente,

$$
\mathrm{VPL}_{2}=\mathrm{VPL}_{A}+\mathrm{VPL}_{B}=46.215,26+315,51=46.530,77 .
$$

Temos então $\mathrm{VPL}_{1}>\mathrm{VPL}_{2}$. Portanto, sob a ótica do VPL, a melhor escolha para Pedro é o curso 1.

Uma grande desvantagem da técnica do VPL é que a rentabilidade do projeto não é apresentada. Em parte, esta é a motivação para o assunto da seção seguinte.

\section{Taxa Interna de Retorno (TIR)}

Todo projeto de investimento traz implicitamente ao menos uma medida de rentabilidade, que pode ser entendida como uma taxa de retorno sobre o capital a ser utilizado. Desta forma, projetos distintos podem ser comparados por meio dessas taxas. Analistas financeiros utilizam muito esta ideia, pois ela mostra o quão rentável é um investimento.

Novamente utiliza-se a ideia de trazer os capitais a valor presente e considerar as taxas que fazem o valor presente do projeto ser nulo, conforme a definição abaixo.

Definição 2. Uma taxa interna de retorno para a série de capitais $c_{0}, \ldots, c_{n}$ é uma taxa $\rho$ tal que

$$
c_{0}+\sum_{i=1}^{n} \frac{c_{i}}{(1+\rho)^{i}}=0 .
$$


Definindo $x=1+\rho$ e multiplicando (8) por $x^{n}$, podemos determinar as taxas internas de retorno encontrando as raízes do polinômio

$$
p(x)=c_{n}+c_{n-1} x+\ldots+c_{0} x^{n} .
$$

Claramente a Definição 2 deve ser seguida de uma discussão sobre a natureza e o número de raízes distintas do polinômio (9), mas muitas vezes esta análise não acontece, ou ocorre de maneira superficial. Veja por exemplo [4], [8], [6].

Sabemos do clássico Teorema Fundamental da Álgebra que existem exatamente $n$ raízes (contanto as multiplicidades) para o polinômio (9). O primeiro problema é que estas raízes podem ser números complexos puros. Por exemplo, considere um projeto financeiro com três entradas ou saídas de caixa $c_{0}, c_{1}$ e $c_{2}$ tais que o número $c_{1}^{2}-4 c_{0} c_{2}$ seja menor que zero. Usando $n=2$ em (9), a fórmula quadrática garante que $p(x)=c_{0} x^{2}+c_{1} x+c_{2}$ possui duas raízes complexas não reais. Um fluxo de caixa simples no qual tal situação ocorre é o da Figura 6.

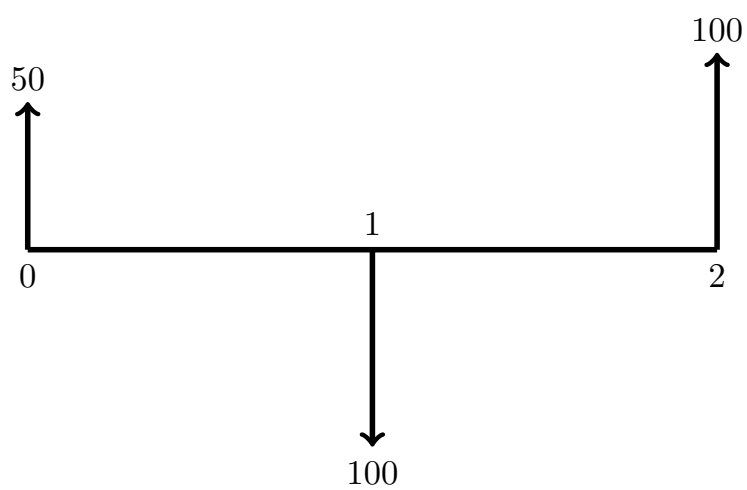

Figura 6: Fluxo de caixa com TIR's complexas

Na notação da Definição 2 temos

$$
50-\frac{100}{1+\rho}+\frac{100}{(1+\rho)^{2}}=0,
$$

donde obtemos a equação quadrática $x^{2}-2 x+2=0$, que não possui raízes reais.

Fluxos de caixa com taxas de retorno todas complexas não necessariamente precisam ser descartados, conforme citado em [6, p199]. Uma análise deste caso é feita em [3]. Contudo, apenas com vistas a limitar a abrangência deste trabalho, não abordaremos esse caso.

Nosso foco está em demonstrar a existência e unicidade da taxa interna de retorno no caso de um projeto financeiro que possui o chamado fluxo de caixa convencional, isto é, desembolsos iniciais $c_{0}, \ldots, c_{i_{0}}$ até a data $i_{0}$ e retornos positivos $c_{i_{0}+1}, \ldots, c_{n}$ a partir de $i_{0}+1$. Veja a Figura 7 . Este não é o caso do exemplo anterior, mas se enquadra perfeitamente no Projeto Faculdade do Pedro.

Teorema 2. Um projeto financeiro com fluxo de caixa convencional possui uma única taxa interna de retorno. 


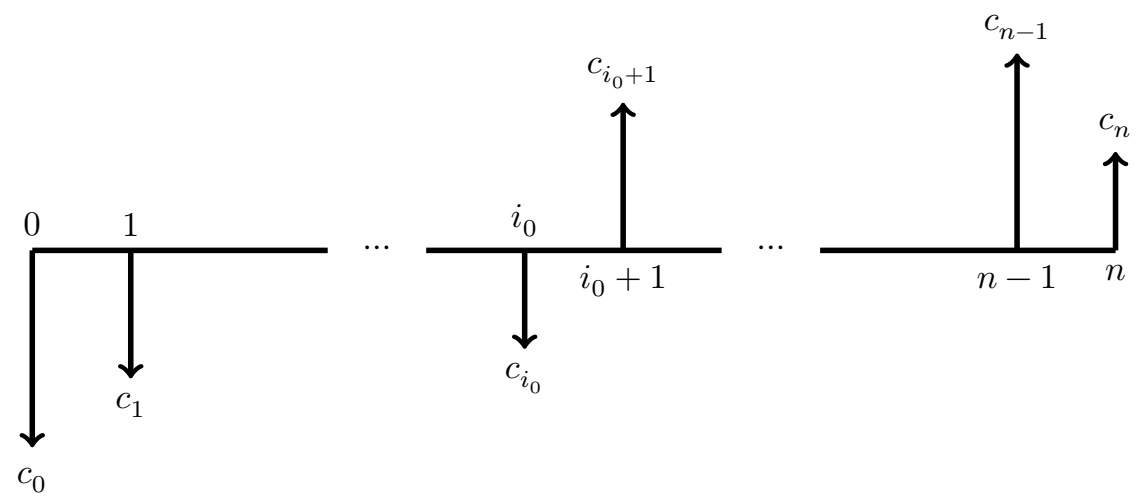

Figura 7: Fluxo de Caixa Convencional

Para demonstrarmos o Teorema 2 necessitamos de uma análise da relação entre o sinal de cada coeficiente do polinômio 9 e seu número de raízes reais positivas, que pode ser obtida usando a clássica Regra de Sinais de Descartes - teorema exposto a seguir. A demonstração está baseada nas ideias de [10]. Um refinamento recente sobre este teorema foi demonstrado em [1]. A Regra de Sinais tem aplicações interessantes no ensino médio. O leitor interessado pode consultar [2], onde também encontrará uma exposição bem mais detalhada do teorema e generalizações.

Teorema 3 (Regra de Sinais de Descartes). O número de raízes reais positivas do polinômio $f(x)=a_{0}+a_{1} x+\ldots+a_{n} x^{n}$, com $a_{i} \in \mathbb{R}$ não nulos, é igual ao número de variações de sinal da sequência dos coeficientes $a_{0}, \cdots, a_{n-1}, a_{n}$, ou um número menor, mas de mesma paridade.

Demonstração. Vamos assumir $a_{n}>0$. A análise para $a_{n}<0$ é análoga. Se $a_{0}=f(0)>0$, então o número de variações de sinal de $a_{0}, \cdots, a_{n-1}, a_{n}$ é obrigatoriamente par, uma vez que o primeiro e o último termo da sequência são positivos. Por outro lado, temos $\lim _{x \rightarrow \infty} f(x)=\infty$. Vejamos que isto implica que o número de raízes positivas também é par. De fato, o gráfico de $f$ cruza o semi-eixo positivo $x$ um número par de vezes, sem cortarmos multiplicidades. Se o gráfico de $f$ toca (sem cruzar) o semi-eixo positivo $x$ no ponto $a$, então a multiplicidade da raiz $a$ é par [2, Lema 2.0.7]. Se o gráfico de $f$ cruza o semi-eixo positivo $x$ na raiz múltipla $x=a$, a multiplicidade de $a$ é ímpar [2, Lema 2.0.6]. Desta forma, as raízes múltiplas contribuem com um número par de raízes positivas. Argumento similar pode ser usado no caso de $a_{0}=f(0)<0$. Neste caso, tanto o número de variações de sinal da sequência dos coeficientes de $f$ como o número de zeros positivos de $f$ são ímpares. Portanto, o número de raízes positivas tem a mesma paridade do número de variações de sinal. Resta agora mostrar que o número de variações de sinal dos coeficientes limita o número de raízes positivas. Para isto utilizaremos indução sobre o grau de $f$. Para $n=1$, a única raiz de $f(x)=a_{0}+a_{1} x$ é positiva se e somente se $a_{0}$ e $a_{1}$ tiverem sinais opostos. Vamos agora assumir que a afirmação é válida para polinômios de grau $\leq n-1$. Supondo que $f$ tem $m$ raízes reais positivas e que a quantidade de variações de sinal da sequência de seus coeficientes é $k<m$, seria necessário termos $m \geq k+2$ para manter a paridade. Agora, a derivada $f^{\prime}(x)=a_{1}+a_{2} x+\ldots+a_{n} x^{n-1}$ tem ao menos $k+1$ raízes reais positivas. De fato, no intervalo aberto entre duas raízes consecutivas de $f$, o Teorema de Rolle garante que há uma raiz para $f^{\prime}$. Mas isso contraria a hipótese indutiva, já que a quantidade de variações de sinal dos coeficientes de $f^{\prime}$ é menor que $k$. Portanto, $m \leq k$. 
À um polinômio da forma mais geral $f(x)=a_{0} x^{\alpha_{0}}+a_{1} x^{\alpha_{1}}+\ldots+a_{n} x^{\alpha_{n}}$, com $a_{i} \in \mathbb{R}$ não nulos e $\alpha_{0}<\alpha_{1}<\ldots<\alpha_{n}$ também se aplica o Teorema, conforme [10].

Utilizando a Regra de Sinais de Descartes podemos facilmente demonstrar o Teorema 2.

Demonstração. (do Teorema 2) Sejam $c_{0}, c_{1}, \ldots, c_{n}$ números reais, $c_{i} \leq 0$ para $i=0, \ldots, i_{0}$ e $c_{j} \geq 0$, para $j=i_{0}+1, \ldots, n$, com ao menos um par $c_{i}, c_{j}$ tal que $c_{i} c_{j} \neq 0$. Da Definição 2, uma taxa interna de retorno para o projeto é uma taxa $\rho$ tal que

$$
c_{0}+\sum_{i=1}^{n} \frac{c_{i}}{(1+\rho)^{i}}=0
$$

Fazendo $x=1+\rho$ e multiplicando a expressão acima por $x^{n}$, obtemos o polinômio $p(x)=$ $c_{n}+c_{n+1} x+\ldots+c_{0} x^{n}$. Notando que há somente uma mudança de sinal nos coeficientes deste polinômio, o Teorema 3 garante que há somente uma raiz positiva $x$, e portanto uma única TIR $\rho$.

Tendo-se um projeto financeiro com fluxo de caixa convencional, pode-se utilizar a TIR como critério para realização ou não deste projeto. A comparação deve ser feita com a taxa mínima de atratividade (TMA), tratada antes da Definição 1 e denotada por $\kappa$. Por exemplo,

- Para um projeto de investimento, é necessário que TIR $>\kappa$.

- Do ponto de vista de um tomador de um empréstimo, deve-se ter TIR $<\kappa$.

Finalmente, entre dois ou mais projetos financeiros distintos com fluxo de caixa convencional, pode ser conveniente comparar suas respectivas taxas internas, conforme o exemplo a seguir.

Suponha que um investidor possua um capital de $\mathrm{R} \$ 120.000,00$ que pode ser investido de duas formas. Na primeira opção os retornos serão de $\mathrm{R} \$ 95.000,00$ após 3 anos, $\mathrm{R} \$ 70.000,00$ após 5 anos e R $\$ 90.000,00$ após 7 anos. Na segunda alternativa, os retornos são de $\mathrm{R} \$ 50.000,00$ após o primeiro ano, $\mathrm{R} \$ 80.000,00$ após 2 anos e $\mathrm{R} \$ 35.000$, 00 após 3 anos. Vejamos qual é a melhor alternativa, admitindo uma TMA de $\kappa=18 \%$ ao ano.

Para a primeira alternativa, temos

$$
120.000-\frac{95.000}{\left(1+\rho_{1}\right)^{3}}-\frac{70.000}{\left(1+\rho_{1}\right)^{5}}-\frac{90.000}{\left(1+\rho_{1}\right)^{7}}=0
$$

Fazendo $x=1+\rho_{1}$ e simplificando, obtemos

$$
24 x^{7}-19 x^{4}-14 x^{2}-18=0 .
$$

Esta equação possui como única raiz real $x \approx 1,17265$. Voltando na troca de variáveis, temos $\rho_{1}=17,26 \%$ ao ano. 
Na segunda opção temos

$$
120.000-\frac{50.000}{\left(1+\rho_{2}\right)}-\frac{80.000}{\left(1+\rho_{2}\right)^{2}}-\frac{35.000}{\left(1+\rho_{2}\right)^{3}}=0 .
$$

Seguindo o mesmo processo, obtemos

$$
24 x^{3}-10 x^{2}-16 x-7=0,
$$

cuja única raiz real é $x \approx 1,18607$. Finalmente, $\rho_{2}=18,61 \%$ ao ano.

Portanto, $\rho_{1}$ é menor que $\rho_{2}$. Ainda, $\rho_{1}<\kappa$, o que nos leva a um VPL negativo para a primeira alternativa. Por outro lado, $\rho_{2}>\kappa$, o que nos dá um VPL positivo para a segunda opção. Segue que a alternativa escolhida deve ser a segunda.

Comparar a taxa interna de retorno nem sempre é condição suficiente para afirmar que se $\mathrm{TIR}_{A}>$ $\mathrm{TIR}_{B}$ então o projeto $A$ deve ser preferido ao projeto $B$. Por exemplo, poderia-se ter duas alternativas de investimentos mutuamente excludentes, como as mostradas na figura abaixo, para uma taxa mínima de atratividade de $20 \%$.

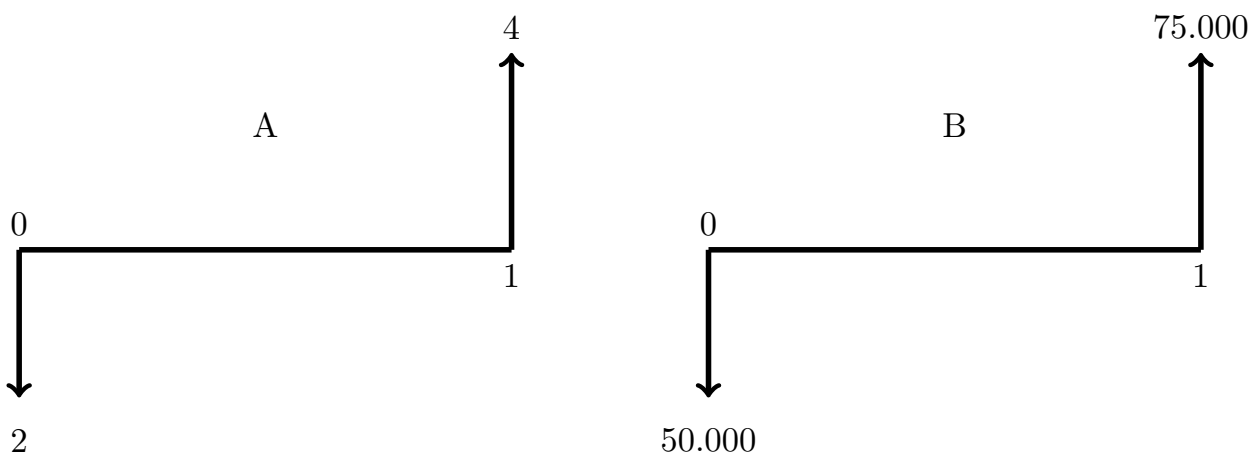

Figura 8: Alternativas Mutuamente Excludentes

A TIR do investimento $A$ é de $100 \%$. Já a do investimento $B$ é de $50 \%$, mas em $A$ temos uma quantia tão pequena, tendo também um rendimento tão baixo que mesmo ela rendendo percentualmente o dobro de $B$, uma vez que haja a disponibilidade de recursos, a alternativa $B$ deve ser escolhida. Este impasse pode ser solucionado aplicando à TMA as diferenças entre os investimentos e as parcelas que retornam.

\section{Múltiplias taxas internas de retorno}

Fluxos de caixa que geram mais de uma taxa interna de retorno são denominados não convencionais. Um exemplo motivatório interessante foi mostrado em [5], na área de prospecção de petróleo. Inicialmente há despesas com pesquisa e outras atividades pré-extração. Em seguida, há vários períodos em que predominam as receitas. Depois tem-se outros períodos nos quais são feitas novas prospecções e despesas a fim de gerar receitas nos anos subsequentes.

Várias outras situações econômicas geram fluxos de caixa deste tipo, de forma que trata-se de um caso de grande relevância prática. O problema não é simplesmente determinar todas as TIR, mas 
saber qual delas faz sentido no problema. Diversas técnicas vem sendo desenvolvidas neste sentido, como por exemplo nos trabalhos [3] e [11].

\section{Referências}

[1] Avendano, M. 2010. Descartes' rule of signs is exact!. Journal of Algebra, v. 324, pp. 2884-2892.

[2] Coutinho, A. C. 2016. A regra dos sinais de Descartes. Dissertação de Mestrado PROFMAT, Universidade Federal Rural de Pernambuco, Disponível em: <http://www.dm.ufrpe.br/sites/ www.dm.ufrpe.br/files/adriano.pdf>. Acesso em: 06 de junho de 2018.

[3] Hartman, J. C., Schafrick, I. C. 2004. The relevant internal rate of return. The Engineering Economist, v. 49, n. 2, p. 139-158.

[4] Filho, N. C., Kopitke, H. 2000. Análise de investimentos: matemática financeira, engenharia econômica, tomada de decisão, estratégia empresarial. São Paulo: Ed. Atlas.

[5] Lorie, J. H., Ssavage, L. J. 1995. Three problems in rationing capital. The Journal of Business, v. 28, n. 4, p. 228-239.

[6] Mathias, W. F., Gomes, J. M. 2002. Matemática Financeira. São Paulo: Ed. Atlas.

[7] Ministério da Fazenda; Tesouro Direto. 2018. Disponível em: <http://www.tesouro.gov.br/ tesouro-direto-entenda-cada-titulo-no-detalhe>. Acesso em: 06 de junho de 2018.

[8] Puccini, E. C. 2011. Matemática financeira e análise de investimentos. Florianópolis: CAPES:UAB.

[9] Silva, J. S. 2017. Equações algébricas e progressões geométricas utilizadas nos métodos de decisão de investimentos baseados no VPL e TIR. Dissertação de Mestrado PROFMAT, Universidade Tecnológica Federal do Paraná. Disponível em: <http://repositorio.utfpr.edu.br/jspui/handle/ 1/2979>. Acesso em: 06 de junho de 2018.

[10] Wang, X. 2004. A simple proof of Descartes's Rule of Signs. The American Mathematical Monthy, v. 111, pp. 525-526.

[11] Zhang, D. 2005. A different perspective on using multiple internal rates of return: the IRR parity technique. The Engineering Economist, v. 50, n. 4, pp. 327-335.

Ronie Dario

UTFPR-Curitiba <ronie@utfpr.edu.br>

Jeferson da Silva

UTFPR-Curitiba $<$ jazzfersound@gmail.com> 